\title{
DESAIN PEMBELAJARAN GARIS BAGI SUDUT DENGAN PENDEKATAN MATEMATIKA REALISTIK
}

\author{
Bagus Ardi Saputro ${ }^{1)}$, Sumarni ${ }^{2)}$ \\ ${ }^{1) 2)}$ Universitas Pendidikan Indonesia ${ }^{1)}$ Universitas PGRI Semarang, \\ ${ }^{2)}$ Universitas Kuningan \\ Email: bagusardisaputro@ student.upi.edu ${ }^{1)}$ marnie.1205@gmail.com ${ }^{2)}$
}

\begin{abstract}
The objective of this research is to find the phenomenon and design the learning with the characteristics of realistic mathematical approach and the scientific approach for the procedure of constructing the line for the angle. This research is research and development which still on the table experiment stage that choose the topic stage, subject matter, concept, and scenario in relevant situation type with the concept. In the development stage obtained the first stage instructional design to determining the seat of advertising tower founded crossroads of three roads selected as a context for learning that leads students beginning in accordance with the characteristics of realistic mathematics approach.the initial design of the first stage of research development was implementation, by tested to three students of mathematics education level II semester 3 at one of the private university on December 2017. The result of design instructional tasted show that begins with the context of establishing advertising tower at the intersection of three streets can be used as an alternative design of line learning for angles. This design is in accordance with the characteristics of a realistic mathematical approach and will be more effective if students are adept at using GeoGebra and using the software in the learning process.
\end{abstract}

Keywords: lines for angles, realistic mathematics

\section{PENDAHULUAN}

Mengkonstruksi garis bagi sudut biasanya dipandang sebagai prosedur matematika yang secara langsung diajarkan kepada siswa. Aktivitas siswa biasa dipandu oleh buku teks yang langsung memberikan prosedur konstruksi garis bagi sudutyang dapat dilihat pada salah satu buku teks terbitan Pusat Perbukuan yang ditulis Wintarti, dkk, (2008) hal. 243 - 244. Tetapi kurikulum 2013 menginginan prosedur tersebut tidak boleh secara langsung diajarkan kepada siswa. Siswa juga harus belajar seolah - olah seperti seorang ilmuan. Mereka menemukan prosedur tersebut dari hasil pengamatan terhadap fenomena atau fakta matematika. Pendekatan tersebut mirip dengan pendekatan matematika realistik. Dimana suatu konteks menjadi acuan awal dalam mengembangkan model sebagai jembatan menuju matematika formal. Aktivitas seperti ini memang merupakan alur desain pembelajaran yang sedang digagas oleh Kurikulum 2013 yang dapat dilihat pada latar belakang buku teks SMP yang diterbitkan oleh Pusat Kurikulum dan Perbukuan, Balitbang, Kemdikbud.

Walaupun begitu, mendapatkan atau mendesain fenomena yang menjembataniprosedur mengkonsrtruksi garis bagi sudut tidaklah mudah. Oleh 
karena itu, diperlukan penelitian untuk menemukan fenomena dan mendesain pembelajaran dengan karakteristik pendekatan matematika realistik dan pendekatan ilmiah untuk prosedur mengkonstruksi garis bagi sudut.

Pembelajaran akan didesain sesuai dengan lima karakteristik dari proses pembelajaran matematika realistik yang terdapat dalam buku Developing Realistic Mathematics Education yang ditulis oleh Gravemeijer (1994) yaitu:

(1) Penggunaan Konteks

\section{(Phenomenological exploration)}

Ide dasar dari Freudenthal yaitu didactical phenomenology, digunakan sebagai titik awal pembelajaran dengan mengeksplorasi suatu kejadian atau fenomena.Didactical phenomenomogy sesuai dengan salah satu prinsip pembelajaran kurikulum 2013, yaitu pembelajaran yang digunakan dari pembelajaran berbasis konten menuju pembelajaran berbasis kompetensi. (Lampiran Permendikbud No. 22 tentang Standar Proses Dikdasmen Tahun 2016)

(2) Penggunaan Model untuk Matematisasi Progresif (Bridging by vertival instruments)

Menggunakan jembatan berupa model untuk menjembatani gap antara intuitive level dan level of subject-matter systematics. Tahapan pembelajaran ini sesuai dengan salah satu prinsip pembelajaran kurikulum 2013, yaitu pembelajaran yang digunakan dari pendekatan tekstual menuju proses sebagai penguatan penggunaan ilmiah. (Lampiran Permendikbud No. 22 tentang Standar Proses Dikdasmen Tahun 2016)

(3) Pemanfaatan Hasil Konstruksi Siswa (Student contribution)

Menggunakan hasil kontruksi dan kerja siswa baik berupa gagasan atau pemahamannya untuk membangun konsep matematika. Prinsip pembelajaran dalam kurikulum 2013, pembelajaran mengutamakan pembudayaan dan pemberdayaan peserta didik sebagai pembelajar sepanjang hayat. (Lampiran Permendikbud No. 22 tentang Standar Proses Dikdasmen Tahun 2016)

(4) Interaktivitas (Interactivity)

Negosiasi, intervensi, diskusi, kerja sama dan evaluasi sebagai elemen penting mengkonstruksi proses pembelajaran dari ide informal yang digunakan siswa hingga mencapai pengetahuan formal. Hal tersebut sesuai dengan pelaksanaan proses pembelajaran yang ditetapkan dalam standar proses, yaitu proses pembelajaran pada satuan pendidikan diselenggarakan secara interaktif, inspiratif, menyenangkan, menantang, memotivasi peserta didik untuk berpartisipasi aktif, serta memberikan ruang yang cukup bagi prakarsa, kreativitas, dan kemandirian sesuai bakat, minat dan perkembangan fisik dan psikologis peserta didik. (Lampiran Permendikbud No. 22 tentang Standar Proses Dikdasmen Tahun 2016)

(5) Keterkaitan (Intertwining)

Menggunakan pendekatan secara menyeluruh, yang menggabungkan aplikasi, yang artinya untaian pengetahuan tidak diajarkan secara terpisah tetapi terjalin dalam pembelajaran yang dieksploitasi dalam pemecahan masalah. Dari pembelajaran parsial menuju pembelajaran terpadu, dari pembelajaran verbalisme menuju keterampilan apliktif. (Lampiran Permendikbud No. 22 tentang Standar Proses Dikdasmen Tahun 2016)

Sedangkan salah satu desain pembelajaran garis bagi sudut yang disajikan oleh buku teks Contextual Teaching and Learning Matematika SMP kelas VII yang ditulis oleh Wintarti dkk (2008) dan biasa dilakukan guru dalam pembelajaran adalah gambarlah busur lingkaran dengan pusat $\mathrm{P}$ dan jari - jari $\mathrm{r}_{1}$ ! Busur tersebut memotong kaki - kai sudut $\mathrm{P}$ di titik A 
dan B. (2) gambarlah busur lingkaran dengan pusat titik A dan jari - jari sebarang! (3) gambarlah busur lingkaran dengan pusat titik $\mathrm{B}$ yang panjang jarijari sama dengan nomor 2 di atas. Namailah titik potong kedua busur
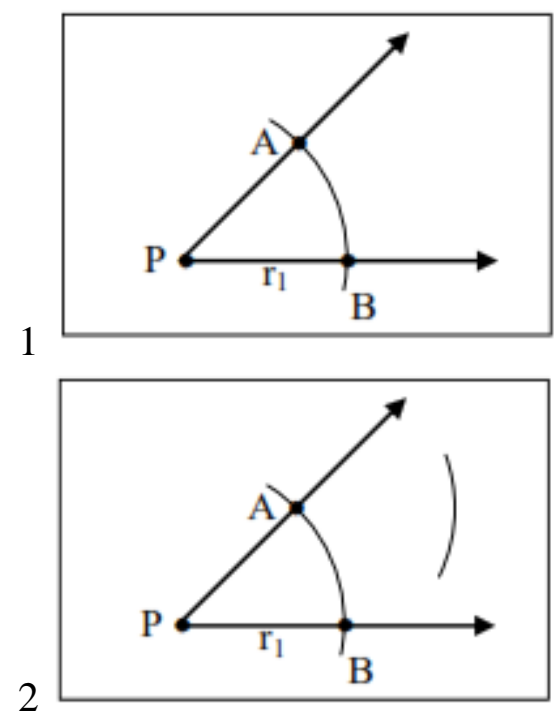

Gambar 1. Tahap Menggambar garis bagi sudut

\section{METODE PENELITIAN}

Penelitian ini merupakan penelitian pengembangan tahap on the table experiment yaitu tahap memilih topik, materi, konsep, dan skenario dalam bentuk situasi yang relevan dengan konsep.

Subjek dalam penelitian ini, yaitu pada tahap uji coba desain bahan ajar adalah tiga mahasiswa Program Prodi Pendidikan Matematika semester 3 tahun ajaran 2016/2017 di salah satu perguruan tinggi swasta pada bulan Desember 2017.

Instrumen yang digunakan dalam penelitian ini adalah desain bahan pembelajaran garis bagi sudut dengan menggunakan pendekatan realistik yaitu melalui permasalahan pendirian tower papan iklan di persimpangan tiga serong kanan. tersebut dengan titik Q! (4) gambarlah garis yang melalui titik $\mathrm{P}$ dan $\mathrm{Q}$. sebut garis tersebut dengan garis $\mathrm{s}$ ! jadi garis $\mathrm{S}$ adalah garis bagi sudut $\mathrm{P}$ menjadi dua bagian sama ukuran.
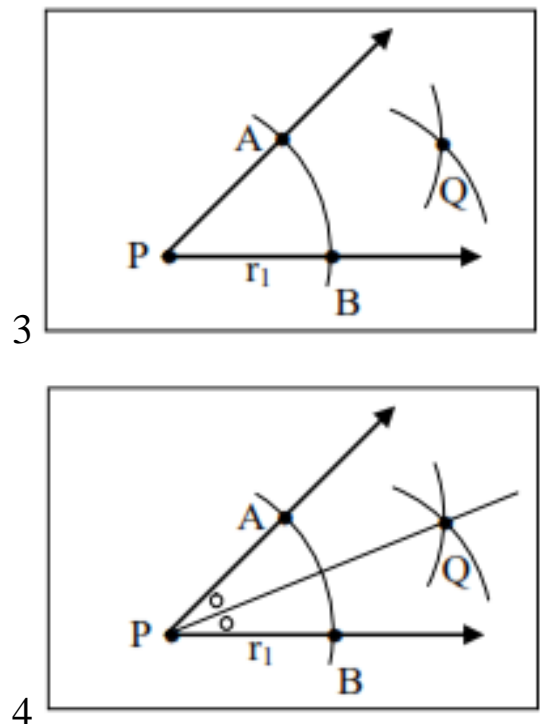

Teknik pengumpulan data melalui uji coba desain pembelajaran garis bagi sudut dengan menggunakan pendekatan realistik yaitu melalui permasalahan pendirian tower papan iklan di persimpangan tiga serong kanan yang telah dikembangkan.

Analisis data dilakukan menggunakan pendekatan deskriptif, terhadap hasil uji coba desain pembelajaran garis bagi sudut dengan menggunakan pendekatan realistik yaitu melalui permasalahan pendirian tower papan iklan di persimpangan tiga serong kanan yang telah dikembangkan.

\section{HASIL PENELITIAN DAN PEMBAHASAN \\ Desain Pembelajaran}


ISSN 2089-8703 (Print) Vol. 6, No. 1 (2017)

ISSN 2442-5419 (Online)

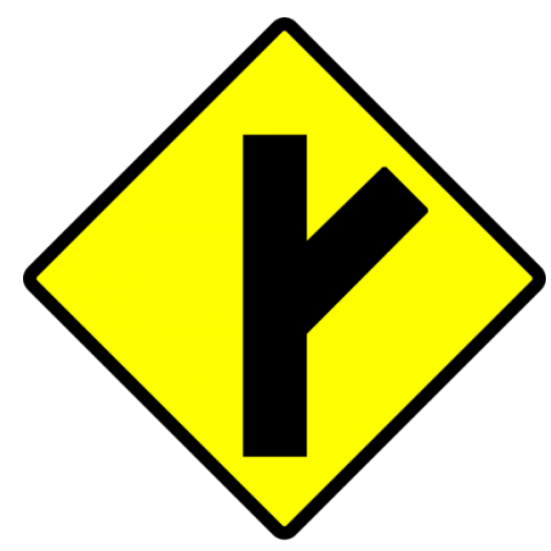

Gambar 2. Persimpangan tiga serong kanan

Pada persimpangan tiga, seorang ingin mendirikan tower sebuah papan iklan. Untuk menghemat biaya, dia akan mendirikan sebuah tower papan iklan yang harus terlihat dari tiga arah jalan yang berbeda. Salah satu tempat yang dianggap strategis yaitu meletakkannya pada area sudut lancip persimpangan tersebut. Dimana dia harus mendirikan tower iklan agar jarak tower tersebut terhadap dua sisi jalan yang mengapit jaraknya sama.

Jika digambarkan menggunakan GeoGebra. Kita bisa menggunakan sebuah garis dan sebuah sinar (lihat gambar 2).

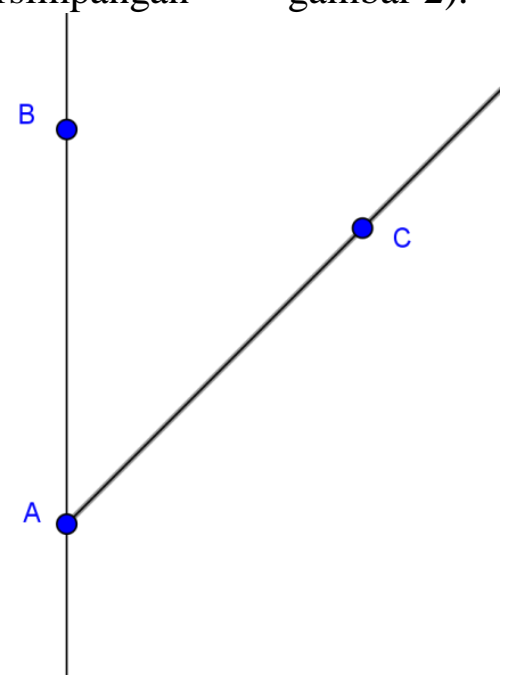

Gambar 3. Model Persimpangan Menggunakan Garis $A B$ dan Sinar $A C$

Tentu banyak sekali tempat diantara garis $\mathrm{AB}$ dan sinar $\mathrm{AC}$ (lihat kedudukan titik - titik yang dapat digunakan untuk mendirikan tower gambar 3). 
ISSN 2089-8703 (Print) Vol. 6, No. 1 (2017)

ISSN 2442-5419 (Online)

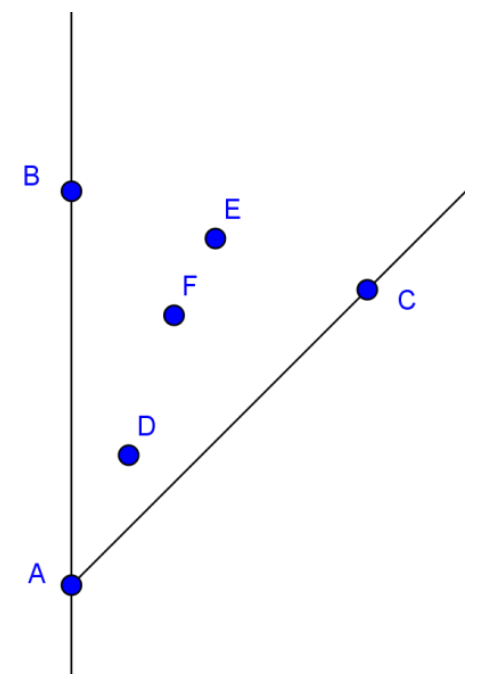

Gambar 4. Titik - titik pada diantara garis AB dan sinar AC

Beberapa

pegawainya

Pertanyaan ini diajukan kepada siswa

mengusulkan titik $\mathrm{D}, \mathrm{E}$ dan F. Akan

tetapi bagaimana kita tahu dan yakin

bahwa titik yang dipilih tersebut berjarak

sama terhadap garis $\mathrm{AB}$ dan sinar $\mathrm{AC}$ ?

untuk dijawab. Sedangkan guru dapat

memperkirakan kemungkinan -

kemungkinan jawaban siswa dan mempersiapkan pertanyaan lanjutan.

Tabel 1. Kemungkinan Jawaban dan Pertanyaan Lanjutan

\section{Kemungkinan Jawaban}

\section{Pertanyaan Lanjutan}

Menentukan titiknya dulu, Bagaimana anda mengukur jaraknya?

kemudian mengukur Bagaimana jika jaraknya berbeda? Apa yang kamu jaraknya ke garis $\mathrm{AB}$ dan lakukan?

mengukur jaraknya ke sinar Bagaimana jika setiap anda mengukur, anda mendapatkan AC. dua jarak yang selalu berbeda?

Apakah ada cara lain agar titik yang kita pilih selalu memiliki jarak yang sama baik terhadap garis $A B$ maupun sinar AC?

Mengukur jarak dari titik ke

Bagaimana anda tahu itu adalah jarak yang terdekat?

garis itu, dipilih jarak yang terdekat.

Jika anda sudah mendapatkan sebuah titik yang berjarak sama terhadap garis $\mathrm{AB}$ dan sinar AC. Apakah ada titik lain yang berjarak sama terhadap garis $\mathrm{AB}$ dan sinar $\mathrm{AC}$ ? Jika jawabannya terdapat lebih dari satu titik yang berjarak sama terhadap garis AB dan sinar AC. Dimanakah letak titik - titik tersebut? 
ISSN 2089-8703 (Print) Vol. 6, No. 1 (2017)

ISSN 2442-5419 (Online)

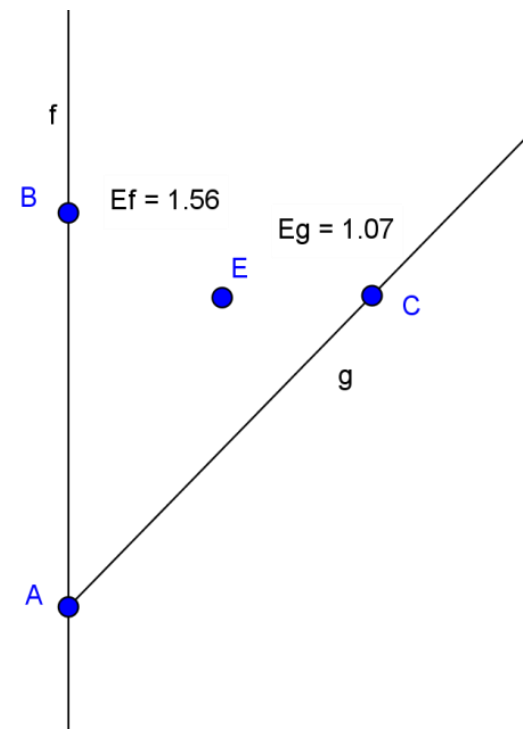

Gambar 5. Model 1 “(1) menentukan titik, (2) mengukur jaraknya”

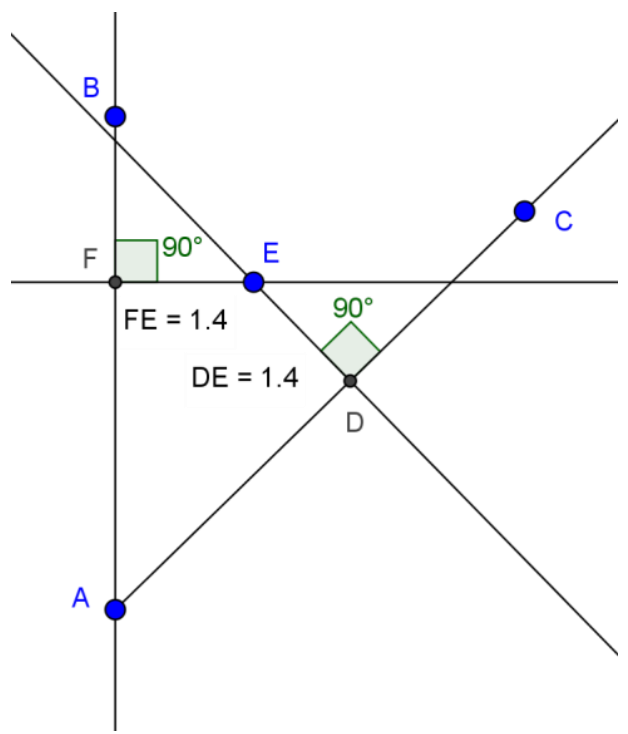

Gambar 6. Model 2 "(1)menentukan titik, (2) membuat garis tegak lurus, (3) mengukur jarak dari titik ke titik potong, (4) menggeser untuk menentukan jarak yang sama

Pada saat siswa mendapatkan titik E yang berjarak sama seperti pada gambar 5. Kemudian ditemukan ternyata ada banyak tempat kedudukan titik $\mathrm{E}$ yang berjarak sama. Munculkan pertanyaan sifat atau ukuran apakah yang selalu tetap saat mendapatkan titik E yang mempunyai jarak yang sama? Jika siswa tidak dapat menjawabnya, munculkan pertanyaan penuntun, apakah jarak FA dan jarak DA selalu sama? Jika jawabannya ya, munculkan pertanyaan kembali. Apa yang dapat kamu manfaatkan ketika mendapatkan sifat tersebut? Jika kamu mengetahui jarak FA dan DA selalu tetap, dapatkah anda menentukan dua titik yang selalu berjarak sama terhadap titik A? Jika jawaban dari siswa belum muncul, berikan pertanyaan apakah kamu dapat memanfaatkan jangka untuk menentukan dua titik tersebut? 
ISSN 2089-8703 (Print) Vol. 6, No. 1 (2017)

ISSN 2442-5419 (Online)

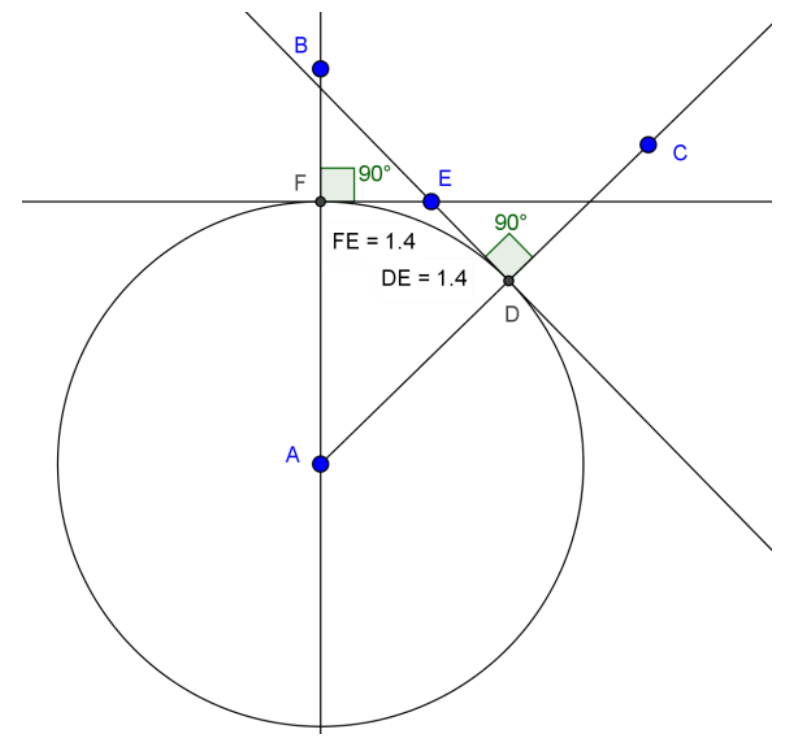

Gambar 7. Membuat lingkaran dengan pusat A melalui D atau F

Pertanyaan selanjutnya adalah sekarang apakah kamu dapat menentukan titik $\mathrm{E}$ yang pasti berjarak sama terhadap garis $\mathrm{AB}$ dan sinar $\mathrm{AC}$ ? Jika jawaban belum keluar, munculkan pertanyaan apakah langkah yang sudah dilakukan dapat dibalik, sehingga kita bisa menentukan titik $\mathrm{E}$ yang selalu berjarak sama terhadap garis $\mathrm{AB}$ dan sinar AC?

Prosedur yang dibalik adalah (1) Membuat titik D pada salah satu kaki AC, (2) Membuat lingkaran dengan pusat A melalui D, (3) Menentukan titik potong lingkaran tersebut dengan kaki sudut yang lain, yaitu kaki sudut $\mathrm{AB}$ sehingga diperoleh titik E. (4) Membuat garis tegak lurus kaki sudut AC melalui titik D, dan garis tegak lurus kaki sudut AB melalui titik E (5) Menentukan titik perpotongan dari dua garis tegak lurus tersebut, sehingga diperoleh titik F. (6) Mengukur jarak FD dan jarak FE. sudut BAC, misalkan pada kaki sudut

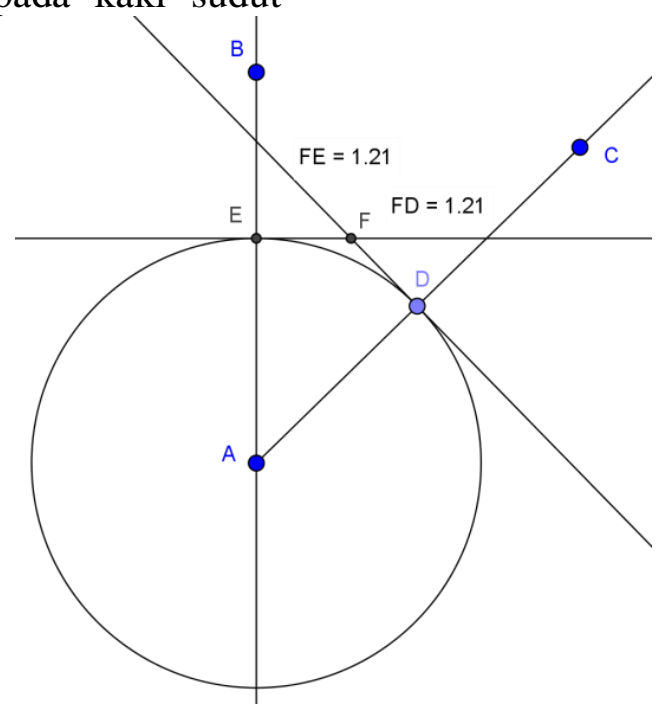

Gambar 8. Prosedur yang dibalik 
ISSN 2089-8703 (Print) Vol. 6, No. 1 (2017)

ISSN 2442-5419 (Online)

Apakah titik $\mathrm{F}$ hanya mempunyai satu kedudukan sehingga berjarak sama terhadap garis $\mathrm{AB}$ dan sinar AC?Jawabannya tentu tidak. Ketika kita menggeser titik D, maka akan diperoleh tempat kedudukan titik - titik yang berjarak sama terhadap garis $\mathrm{AB}$ dan sinar AC. Dengan mengaktifkan jejak "trace" titik E dan menggeser titik D. Kita akan mendapatkan jejak - jejak tempat kedudukan titik - titik yang berjarak sama terhadap garis $\mathrm{AB}$ dan sinar AC.

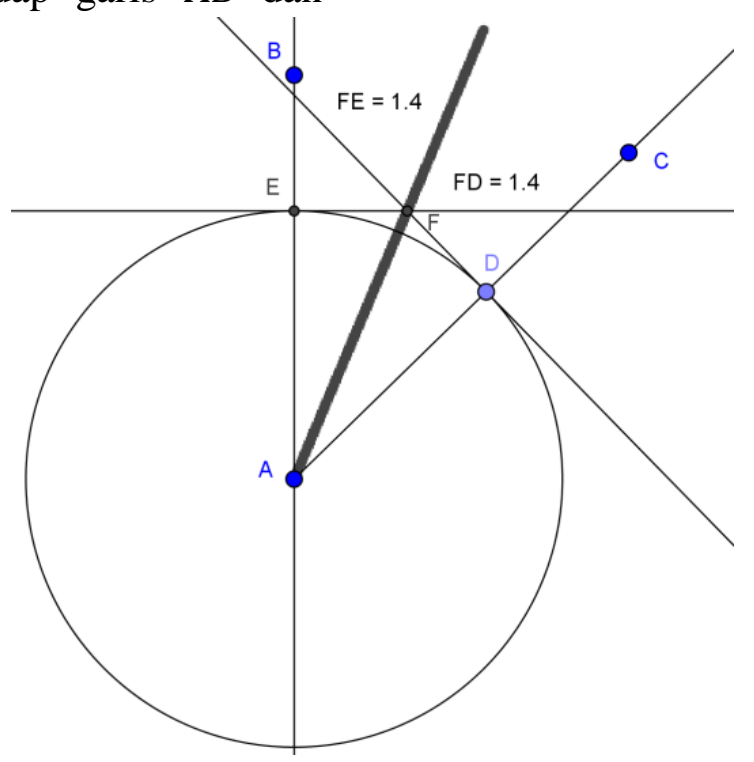

Gambar 9. Jejak titik - titik yang berjarak sama

Apakah jejak titik - titik tersebut membentuk sebuah sinar? Jawabnya "Ya". Dapatkah kita menentukan sinar tersebut? Jawabnya "Ya' dengan membuat sinar dari titik A ke titik F.
Pada tool GeoGebra terdapat fasilitas untuk membuat sinar tersebut, yaitu dengan menggunakan tool"garis bagi sudut" atau "angle bisector".

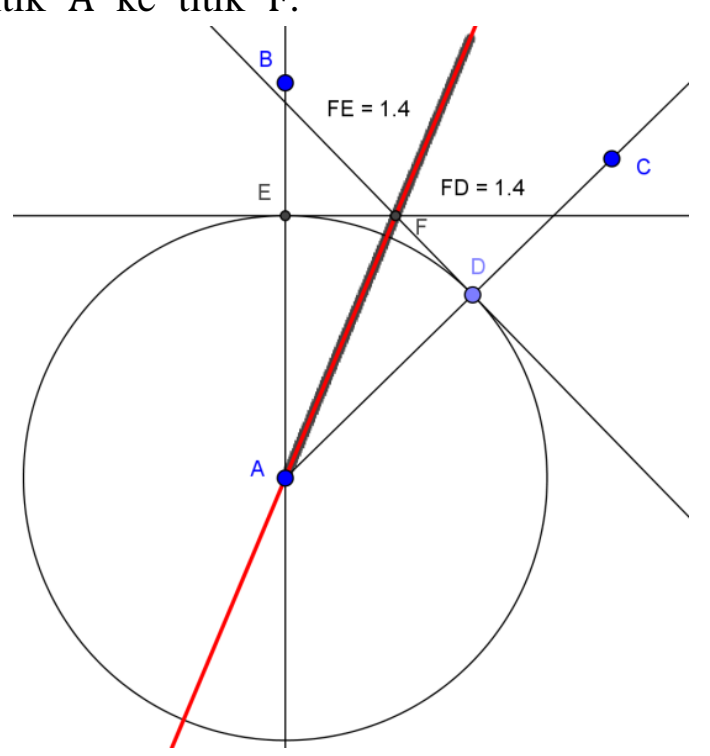

Gambar 10. Garis bagi sudut 
ISSN 2089-8703 (Print) Vol. 6, No. 1 (2017)

ISSN 2442-5419 (Online)

Cara menggunakan tool "garis bagi sudut": klik titik C, klik titik A, klik titik B.Apakah ada cara lain untuk mendapatkan titik F ketika kita sudah mendapatkan titik $\mathrm{D}$ dan titik $\mathrm{E}$ ? Jawabannya: ada, yaitu dengan membuat lingkaran dengan pusat Dmelalui E, dan membuat lingkaran dengan pusat $\mathrm{E}$ melalui D. Kedua lingkaran tersebut berpotongan, salah satu titik potongnya merupakan titik F. Garis yang melalui titik A dan titik $\mathrm{F}$ adalah garis bagi sudut.

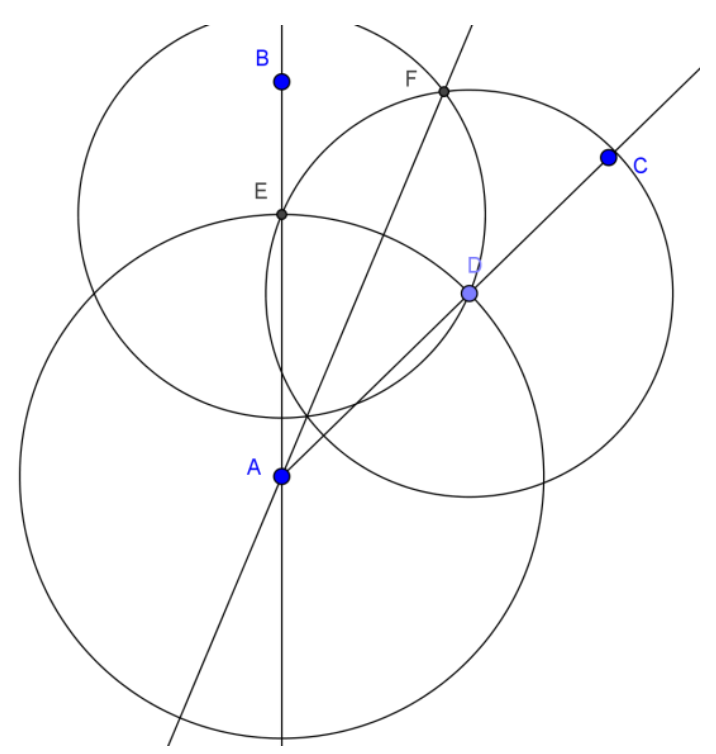

Gambar 11. Garis bagi sudut dengan dua lingkaran yang berpotongan

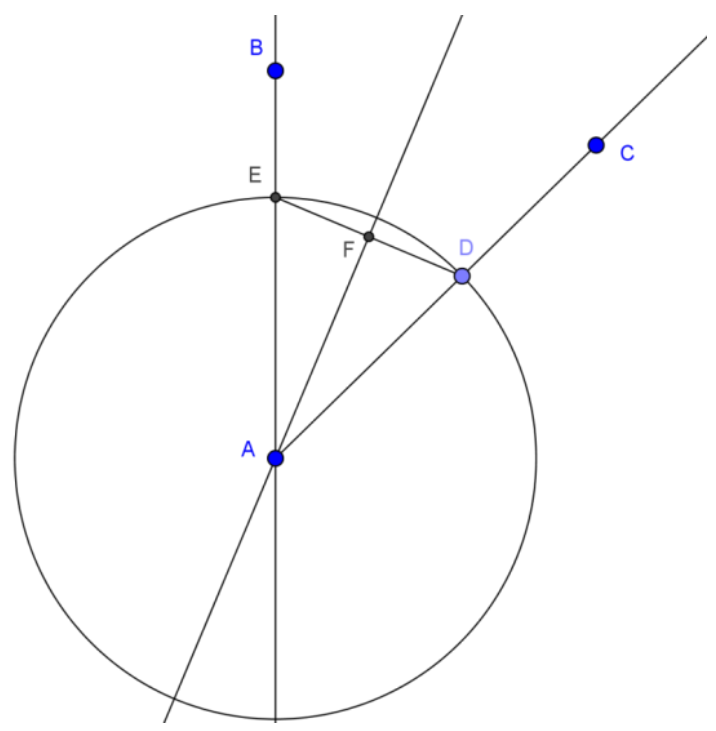

Gambar 12. Garis bagi sudut dengan (1) membuat ruas garis DE, (2) membuat garis bagi tegak lurus DE menggunakan tool "perpendicular bisector", (3) menentukan titik potong garis tersebut dan ruas garis $\mathrm{DE}$ yaitu $\mathrm{F}$.

Ketika kita mendapatkan titik F Dengan bantuan tool "locus" kita bisa pada gambar 9 atau pada gambar 10 . menggambar sinar AF. Caranya klik titik 
ISSN 2089-8703 (Print) Vol. 6, No. 1 (2017)

ISSN 2442-5419 (Online)

F, kemudian klik titik D. loc1 adalah sinar yang kita dapatkan, yang merpakan

berjarak sama terhadap garis $\mathrm{AB}$ dan tempat kedudukan titik - titik yang sinar AC.

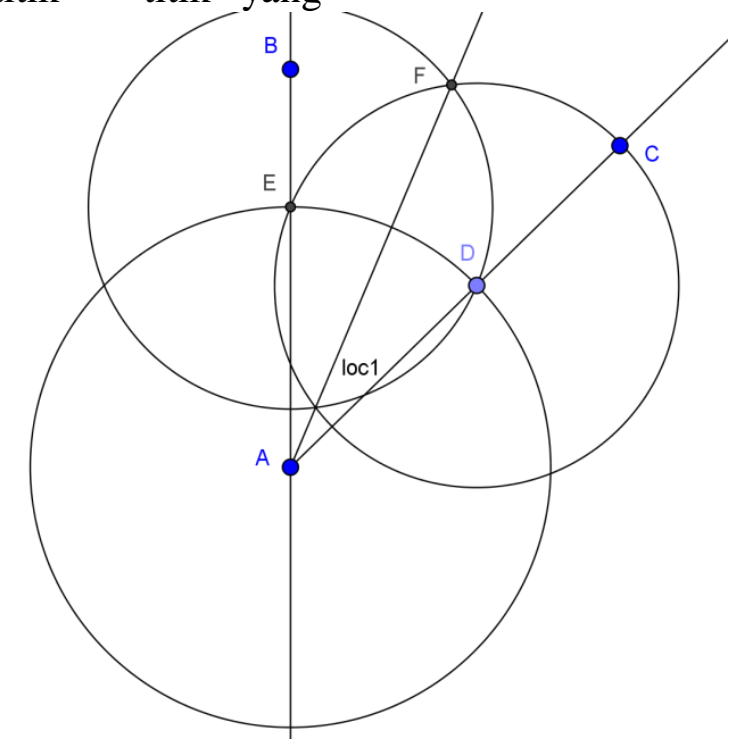

Gambar 13. Locus

Hasil Uji Coba Desain Pembelajaran Desain pembelajaran ini diujicobakan kepada mahasiswa pendidikan matematika tingkat II semester 3 pada salah satu perguruan tinggi swasta pada bulan Desember
2017. Saat diajukan pertanyaan untuk menggambarkan konteks pendirian tower papan iklan di pesimpangan tiga serong kanan peserta didik menggambarkannya sebagai berikut:

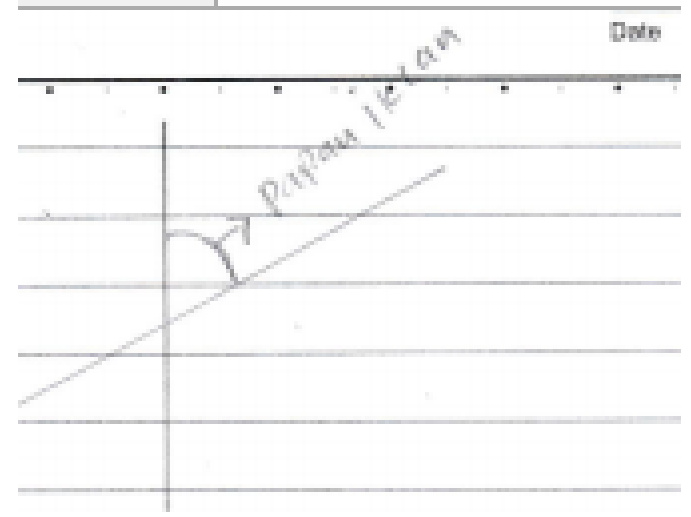

Gambar 14. Model Geometri dari Masalah

Saat diminta untuk mendirikan tower papan iklan agar jarak tower iklan terhadap dua sisi jalan yang mengapit sama, peserta didik menggambarkannya sebagai berikut. 
ISSN 2089-8703 (Print) Vol. 6, No. 1 (2017)

ISSN 2442-5419 (Online)

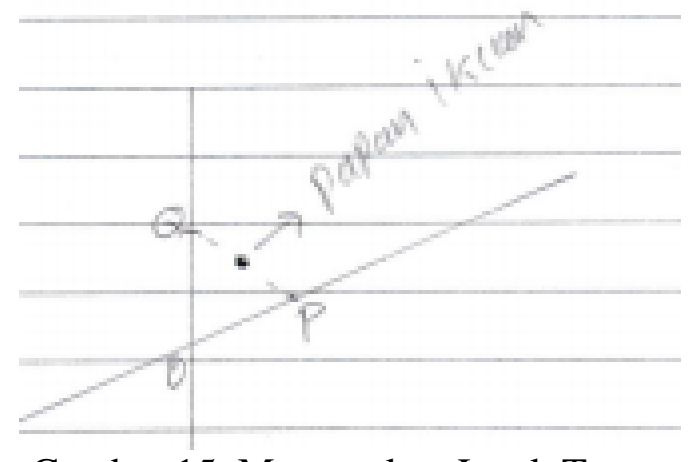

Gambar 15. Menentukan Letak Tower

Berikut hasil wawancara

P: Bagaimana kamu menentukan titik/letak papan iklan tersebut?

$\mathrm{M}$ : dengan cara menentukan titik $\mathrm{P}$ dan membuat titik baru / titik Q dengan jarak titik P dan titik Q sama dari titik sudut, kemudian baru menentukan titik latak papan iklan sehingga titik papan iklan itu merupakan titik tengah antara PQ

$P$ : jika titik letak papan iklan tersebut dinamai dengan titik $\mathrm{S}$, apakah $\mathrm{PS}=\mathrm{SQ}$ ? Mengapa?

$\mathrm{M}$ : iya $\mathrm{PS}=\mathrm{SQ}$ karena $\mathrm{S}$ itu titik tengah PQ.

P: Bagaimana cara kamu menentukan titik P dan titik Q?

$\mathrm{M}$ : mengukur dengan menggunakan penggaris $\mathrm{Bu}$ ?
P: apakah ada cara lain untuk menentukan titik Q jika kita sudah menentukan titik $\mathrm{P}$ agar jarak titik sudut dengan titik $\mathrm{P}$ dan $\mathrm{Q}$ sama?

M: diam dan menjawab dengan cara apa ya bu?

P: bisa tidak dengan menggunakan Jangka?

M: oh iya bu, bisa menggunakan jangka.

P: apakah ada posisi untuk papan iklan tersebut selain titik yang tadi digambarkan?

M: Mmmm, ada bu. Yang penting syaratnya jarak antara kedua jalan dan titik papan iklan itu sama kan bu?

P: iya, bisa gambarkan untuk letak papan iklan yang lainnya?

M: bisa bu seperti ini.

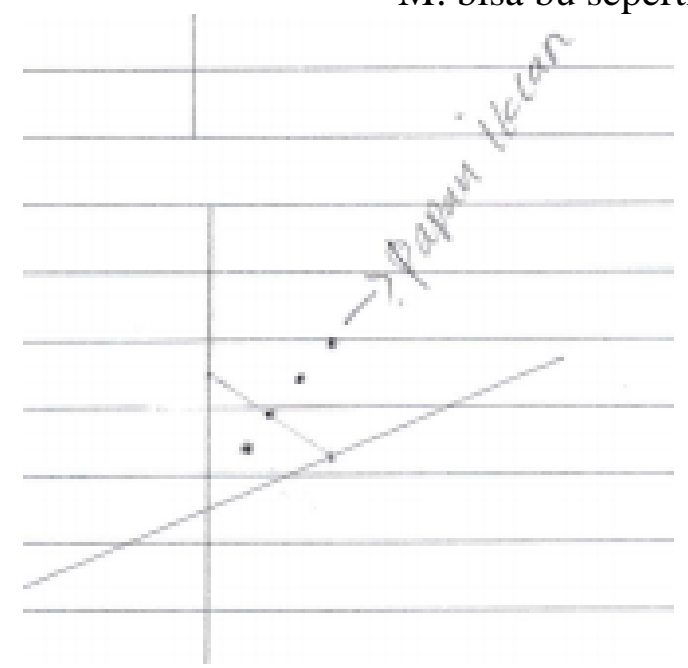

Gambar 16. Menentukan Tempat Kedudukan Tower yang Lain

$\mathrm{P}$ : mengapa kamu menggambarkannya seperti itu?
M: iya bu, saya membuat titik titik yang segaris saja dengan titik tengah yang 
ISSN 2089-8703 (Print) Vol. 6, No. 1 (2017)

ISSN 2442-5419 (Online)

pertama, biar jaraknya sama dengan kedua garis yang disampingnya.

$\mathrm{P}$ : oh, bagaimana jika menggunakan jangka? Dapatkah kamu menentukan titik yang merupakan papan iklan tersebut?Silahkan pergunakan jangka untuk menentukan titik letak papan iklan tersebut.

$\mathrm{M}$ : baik bu, saya coba.

P: ya silahkan coba digambarkan.

M: seperti ini bu.

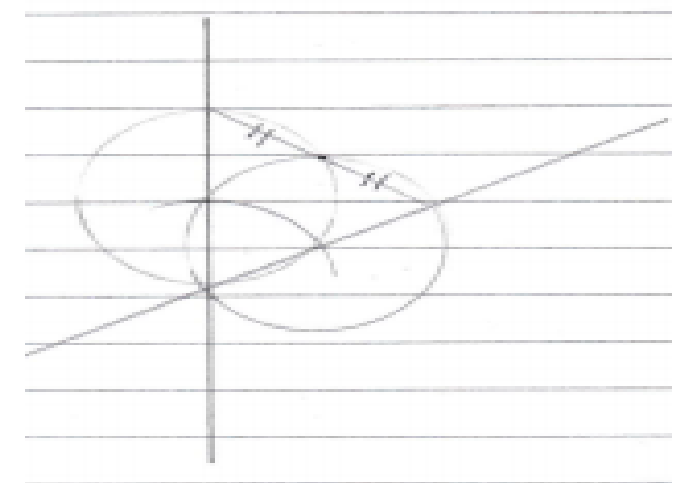

Gambar 17. Menemtukan Tempat Kedudukan Menggunkan Jangka

P: baik, apakah kamu bisa mendeskripsikan terkait gambar yang tersebut?

$\mathrm{M}: \mathrm{Mmm}$, mendeskripsikan apanya bu? $\mathrm{P}$ : misalnya mendeskripsikan jarak titik perpotongan kedua lingkaran dengan titik pada garis yang mengapit itu bagaimana?

M : oh, jarak titik perpotongan kedua lingkaran dengan titik yang mengapit itu sama besar bu?

$\mathrm{P}$ : sama besar? Benar "sama besar"?Untuk mendeskripsikan ukuran jarak?

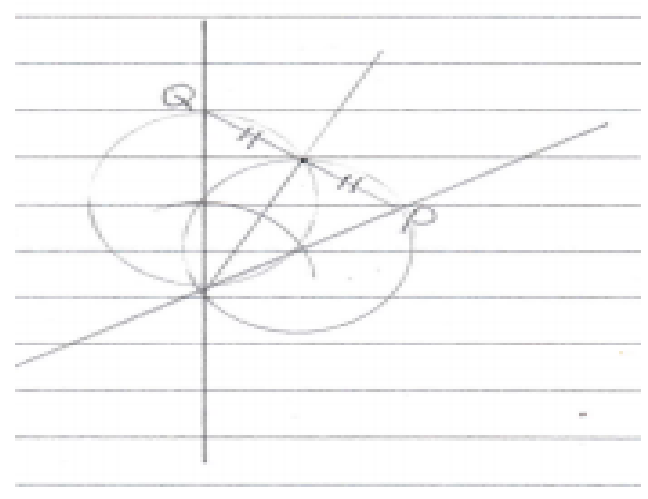

Gambar 18. Menggambar Garis Bagi Sudut
M: eh, bukan sama besar ya bu, sama panjang harusnya bu.

P: baik berarti sama panjang ya, untuk jarak titik papan iklan dan titik P dan Q. Lalu apa lagi yang bisa kamu deskripsikan dari gambar tersebut?

$\mathrm{M}: \mathrm{Mmm} . .$. apa lagi ya bu?

P: coba sekarang kamu tarik garis dari titik sudut melalui titik perpotongan kedua lingkaran

$\mathrm{M}$ : baik bu, seperti ini bu? 
$\mathrm{P}$ : baik, coba perhatikan kembali gambarnya. Apakah yang bisa kamu deskripsikan selain jarak titik $\mathrm{P}$ dan $\mathrm{Q}$ ke titik papan iklan yang sama? Bagaimana dengan sudutnya?

M: oh iya bu, sudutnya sama ya bu?

$\mathrm{P}$ : apakah kamu masih ingat konsep apa yang kamu gambarkan tadi?

M : konsep ya bu, jarak papan iklan dengan kedua jalan sama ya bu sayaratnya.

$\mathrm{P}$ : iya, selain itu tadi juga kan besar kedua sudut nya juga sama kan?

$\mathrm{M}$ : iya bu itu kl tidak salah konsep sudut bagi ya bu, seingat saya dulu saya membuat itu saat di SMA.

P : "sudut bagi" atau "garis bagi"?

$\mathrm{M}$ : eh iya bu, garis bagi.

$\mathrm{P}$ : jadi apa yang bisa disimpulkan dari permasalahn yang ibu berikan terkait permasalahan mendirikan tower papan iklan agar jarak tower iklan terhadap dua sisi jalan yang mengapit sama.

M : berarti untuk mendirikan tower papan iklan agar jarak tower papan iklan sama dengan dua sisi jalan yang mengapit sama maka gunakan konsep garis bagi.

Berdasarkan hasil uji coba bahan ajar yang telah dikembangkan, mahasiswa sudah mampu membuat gambar geometri dari situasi yang disajikan (lihat Gambar 13). Karena pada dasarnya mahasiswa sudah pernah mempelajari konsep garis bagi sudut, maka mahasiswa juga mampu dalam menentukan titik untuk mendirikan tower (lihat Gambar 14). Akan tetapi, untuk menentukan titik $\mathrm{P}$ dan $\mathrm{Q}$ mahasiswa melakukan pengukuran dari titik $\mathrm{O}$ ke titik $\mathrm{P}$ kemudian menggunakan jarak tersebut untuk digunakan sebagai Penggunaan Konteks

Konteks yang digunakan untuk belajar garis bagi sudut adalah membangun tower iklan pada persimpangan tiga jalan. Konteks juga dilengkapi gambar rambu jalan jarak dari O ke titik Q. Mahasiswa juga masih mengukur untuk menentukan letak tower papan iklan berdiri, dengan cara mengukur titik $\mathrm{P}$ dan $\mathrm{Q}$ kemudian membagi dua jaraknya.

Untuk membuat tempat kedudukan titik titik tower papan iklan yang mempunyai sifat yang sama dengan titik tower pada gambar 14, mahasiswa berpedoman pada titik sudut $\mathrm{O}$ dan titik tower yang pertama. Dengan menggunakan penggaris kedua titik tadi, mahasiswa membuat titik titik lain yang segaris dengan kedua titik tadi (lihat Gambar 15).

Saat mahasiswa ditanya tentang prosedur menggambar titik tower papan iklan menggunakan jangka, mahasiswa juga mampu menggambarnya dengan baik (lihat Gambar 16). Kemudian saat ditanya kembali untuk memastikan bahwa titik yang didapat berjarak sama dengan dua kaki sudut,mahasiswa menunjukkannya dengan menggambar ruas garis yang melewati titik tersebut dan memotong dua kaki sudut, serta memberikan simbol bahwa ruas garis tersebut berjarak sama.

Langkah selanjutnya adalah pengajar meminta untuk menggambar garis dari titik sudut ke titik perpotongan dua lingkaran (lihat Gambar 17). Setelah itu mahasiswa di tanya tentang konsep yang digunakan dalam menyelesaikan permasalahan dalam konteks tower papan iklan yang diberikan. Akhirnya mahasiswa dapat memahami bahwa konsep garis bagi sudut yang digunakan.

Rancangan desain pembelajaran garis bagi sudut yang dikembangkan memenuhi karakteristik pendidikan matematika realistik.

persimpangan tiga serong kanan, sebagai suatu tanda yang sudah familier dengan siswa. Menurut Freudenthal (Wijaya, 2012) proses belajar peserta didik hanya akan terjadi jika pengetahuan (knowledge) yang dipelajari bermakna 
bagi peserta didik. Lebih lanjut CORD (Wijaya, 2012) mengemukakan bahwa suatu pengetahuan akan menjadi bermakna bagi peserta didik jika proses pembelajaran dilaksanakan dalam suatu konteks. Konteks membangun tower iklan pada persimpangan tiga jalan dan dilengkapi gambar rambu jalan persimpangan tiga serong kanan, yang sudah familiar bagi siswa adalah permasalahan realistik yang digunakan sebagai fondasi dalam membangun konsep garis bagi sudut.

\section{Penggunaan Model}

Model yang tepat untuk menggambar situasi persimpangan tiga serong kanan adalah menggunakan garis dan sinar (lihat gambar 2). Penggunaan modelsituasi persimpangan tiga serong kanan berfungsi sebagai jembatan dari konsep matematika konkrit menuju konsep matematika formal.

\section{Pemanfaatan Hasil Konstruksi Siswa}

Hasil konstruksi siswa berupa model 1 dan model 2 yang tersaji pada gambar 3 dan gambar 4 yang berupa prosedur untuk mendapatkan titik yang berjarak sama terhadap sinar dan garis. Dimanfaatkan oleh guru untuk mendapatkan prosedur terbaik dalam menentukan titik tersebut. Dalam pembelajaran matematia realistik siswa ditempatkan sebagai subjek belajar yang mengkonstruksi konsep garis bagi sudut. Proses ini tidak hanya membantu siswa memahami konsep garis bagi sudut tetapi juga mengembangkan aktivitas dan kreativitas siswa dalam menentukan garis bagi sudut.

\section{Interaktivitas}

Komunikasi antara guru dan siswa, antara siswa dengan siswa lain terjadi sebagai proses tanya jawab dan berdiskusi untuk mendapatkan prosedur mendapatkan titik yang berjarak sama terhadap sinar dan garis. Menurut Wijaya (2012) pemanfaatan interaksi dalam pembelajaran matematika bermanfaat dalam mengembangkan kemampuan kognitif dan afektif siswa secara simultan. Sehingga pembelajaran realistik sangat sesuai dengan kurikulum 2013 (Permendikbud No. 23 tentang Standar Penilaian Dikdasmen Tahun 2016) dimana penilaian hasil belajar peserta didik meliputi aspek sikap, pengetahuan dan keterampilan.

\section{Keterkaitan}

Konsep garis bagi sudut mempunyai keterkaitan dengan konsep lain seperti, "garis tengah tegak lurus (gambar 11)", "garis tegak lurus (gambar $5 \mathrm{~s} / \mathrm{d}$ gamabr 9)", "keterampilan menggunakan jangka", dan "lokus (gambar 12)". Tema "tanda lalu lintas" memungkinkan siswa belajar tentang kedisiplinan, dan taat akan aturan lalu lintas.

Sedangkan penggunaan GeoGebra dapat memberikan kesempatan kepada siswa untuk bereksplorasi. Hal ini sesuai dengan pendapat dari (Dogan \& Icel, 2011) GeoGebra dapat digunakan untuk mengkonstruksi geometri secara dinamis, sebagai elemen kunci dari pembelajaran geometri, visualisasi, estimiasi, konjektur, konstruk, penemuan dan pembuktian. NCTM (2000) \& Fluck (2010), kemajuan teknologi informasi dan komunikasi (TIK) dapat membantu siswa dan guru untuk melakukan perhitungan, analisis data, mengeksplorasi konsep matematika sehingga meningkatkan pemahaman dalam belajar matematika.Hal ini sesuai dengan pendapat Saha (2010) dan Hohenwater (2009) bahwa visualisasi dan eksplorasi terhadap objek dan konsep matematika dalam lingkungan multimedia dapat mengembangkan pemahaman melalui cara yang baru.

Prosedur yang dikonstruksi mahasiswaserupa dengan prosedur yang ada pada gambar 11. Perbedaaannya adalah garis bagi sudut yang dikonstruksi belum memperlihatkan 
bahwa garis bagi tersebut tegak lurus dengan ruas garis PQ yang ada pada Gambar 17. Tetapi mereka memahami bahwa garis tersebut melewati titik sudut.

\section{KESIMPULAN DAN SARAN}

Pada tahap pengembangan desain pembelajaran diperoleh desain awal bahan pembelajaran untuk menentukan tempat kedudukan tower iklan yang didirikan dipersimpangan tiga jalan dipilih sebagai konteks yang mengantarkan peserta didik diawal pembelajaran yang sesuai dengan karakteristik pendekatan matematika realistik.Selanjutnya, hasil uji coba desain pembelajaran menunjukkan bahwa pembelajaran yang diawali dengan konteks mendirikan tower iklan di persimpangan tiga jalan dapat dijadikan salah satu alternatif desain pembelajaran garis bagi sudut. Desain ini sudah sesuai dengan karakteristik pendekatan matematika realistik dan akan lebih efektif jika siswa mahir menggunakan GeoGebra serta menggunakan software tersebut dalam proses pembelajaran.Selanjutnya desain ini telah diuji cobakan dalam kelas untuk melihat efektifitasnya jika dibandingkan dengan desain pembelajaran yang lain.

\section{DAFTAR PUSTAKA}

Depdiknas. (2016). Permendikbud Nomor 22 Tahun 2016 Tentang Standar Proses Pendidikan Dasar dan Menengah.

Depdiknas. (2016). Permendikbud Nomor 23 Tahun 2016 Tentang Standar Penilaian Pendidikan Dasar dan Menengah.

Dogan, M. \& Icel, R. (2011). The Role of Dynamic Geometry Software in the Process of Learning: GeoGebra Example about Triangles. Journal of
Human Sciences: [1 Desember 2016] www.InsanBlimleri.com/En

Gravemeijer, $\quad$ K. P. E. (1994). Developing Realistic Mathematics Education: Ontwikkelen Van Realistisch Reken/wiskundeonderwijs. CD-[beta] Press.

Hohenwater, M., Jarvis, D., \& Lavicza, Z. (2009). Introducting Dynamic Mathematics Software to Secondary School Teachers: The Case of GeoGebra. International Journal for Technology in Mathematics Education: Research Information Ltd.

National of Council Teacher of Mathematics.(2000). Curricullum and Evaluation Standards for School Mathematics. Reston, VA: NCTM

Saha, R., A., Ayub, A., F., M., \& Tarmizi, R., A. (2010). The Effects of GeoGebra on Mathematics Achievment: Enlightening Coordinate Geometry Learning. International Conference on Mathematics Education research 2010 (ICMER 2010): Elsevier.

Voorst, V. (1999).Technology in mathematics Teacher Education.[1 Desember 2016] www.icte.org/T99_Library/T99_54.P DF.

Wijaya, A. (2012). Pendidikan Matematika Realistik Suatu Alternatif Pendekatan Pembelajaran Matematika. Yogyakarta: Graha Ilmu.

Wintarti, A., dkk. (2008) Contextual Teaching and Learning Matematika: Sekolah Menengah Pertamal Madrasah Tsanawiyah Kelas VII Edisi 4. Jakarta: Pusat Perbukuan, Departemen Pendidikan Nasiona 